\title{
Do Além São Francisco ao Novo Oeste: uma investigação das políticas do Estado ao longo da formação territorial
}

\section{Maria Aparecida Brito Oliveira}

\section{Introdução}

A presente investigação direciona-se a analisar a trajetória das políticas territoriais voltadas à porção oeste do território baiano num recorte da sua formação territorial, entre os anos de 1889 e 2014. Evidencia-se que este processo se configurou de modo concentrado e seletivo, no tempo e no espaço. $\mathrm{Na}$ escala temporal de 125 anos, as ações se efetivaram principalmente nas últimas duas décadas do século XX, pós-1980; já na escala territorial, pouco mais de dez municípios de um total de $35^{1}$, que compreendem toda a porção ocidental da Bahia (Figura 1), concentraram um maior quantitativo de políticas, apontando as contradições inerentes ao papel desempenhado pelo Estado neste território.

A pesquisa concentrou esforços no levantamento de informações a respeito das concepções de

\section{||||||||||||||||||||||||||||||||||||}

1 Os municípios em questão são: Angical, Baianópolis, Barra, Barreiras, Brejolândia, Buritirama, Campo Alegre de Lourdes, Canápolis, Carinhanha, Casa Nova, Catolândia, Cocos, Coribe, Correntina, Cotegipe, Cristópolis, Feira da Mata, Formosa do Rio Preto, Jaborandi, Luis Eduardo Magalhães, Mansidão, Muquem do São Francisco, Pilão Arcado, Remanso, Riachão das Neves, Santa Maria da Vitória, Santa Rita de Cássia, Santana, São Desidério, São Felix do Coribe, Serra do Ramalho, Serra Dourada, Sitio do Mato, Tabocas do Brejo Velho e Wanderley. políticas territoriais direcionadas para o território baiano localizado à margem esquerda do Rio São Francisco ao longo da sua formação, bem como suas implicações territoriais destacando os tipos e conteúdos destas ações. Tornou-se fundamental ainda questionar quais municípios receberam um maior quantitativo de ações e evidenciar os períodos de maior e menor atuação do Estado em termos de políticas, projetos e obras.

A definição de Políticas Territoriais discutidas neste trabalho se baseia na contribuição de autores como Sánchez (1992), Costa (2011), Moraes (2005; 2011a) e Ruckert (2004, 2010), cujas perspectivas reunidas apontam por considerar que as políticas territoriais, de um modo em geral, sejam toda e qualquer ação (programa, projeto ou obra), em suas múltiplas escalas e dimensões, promovidas pelos variados poderes (centrais, regionais e locais), de forma a modificar e qualificar o modo de atuação do Estado sobre um determinado recorte territorial. Neste sentido, serão apresentados os principais conteúdos das políticas voltadas para a parte mais ocidental da Bahia, bem como suas implicações socioterritoriais.

Metodologicamente, as políticas territoriais foram divididas em dois blocos (Quadro 1). As informações são fruto da pesquisa de campo

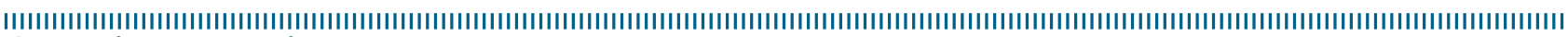
Como citar este artigo:

OLIVEIRA, Maria Aparecida Brito de. “Do Além São Francisco ao Novo Oeste: uma investigação das políticas do Estado ao longo da formação territorial”. In: RÜCKERT, A. A.; SILVA, A. C. P. da; SILVA, G. de V. (Orgs.). Geografia Política, Geopolítica e Gestão do Território: integração sul-americana e regiões periféricas. Porto Alegre: Editora Letra1, 2018, p. 305-318 DOI 10.21507/9788563800367-19 
Figura 1. Municípios investigados na pesquisa, Oeste Baiano 2014.

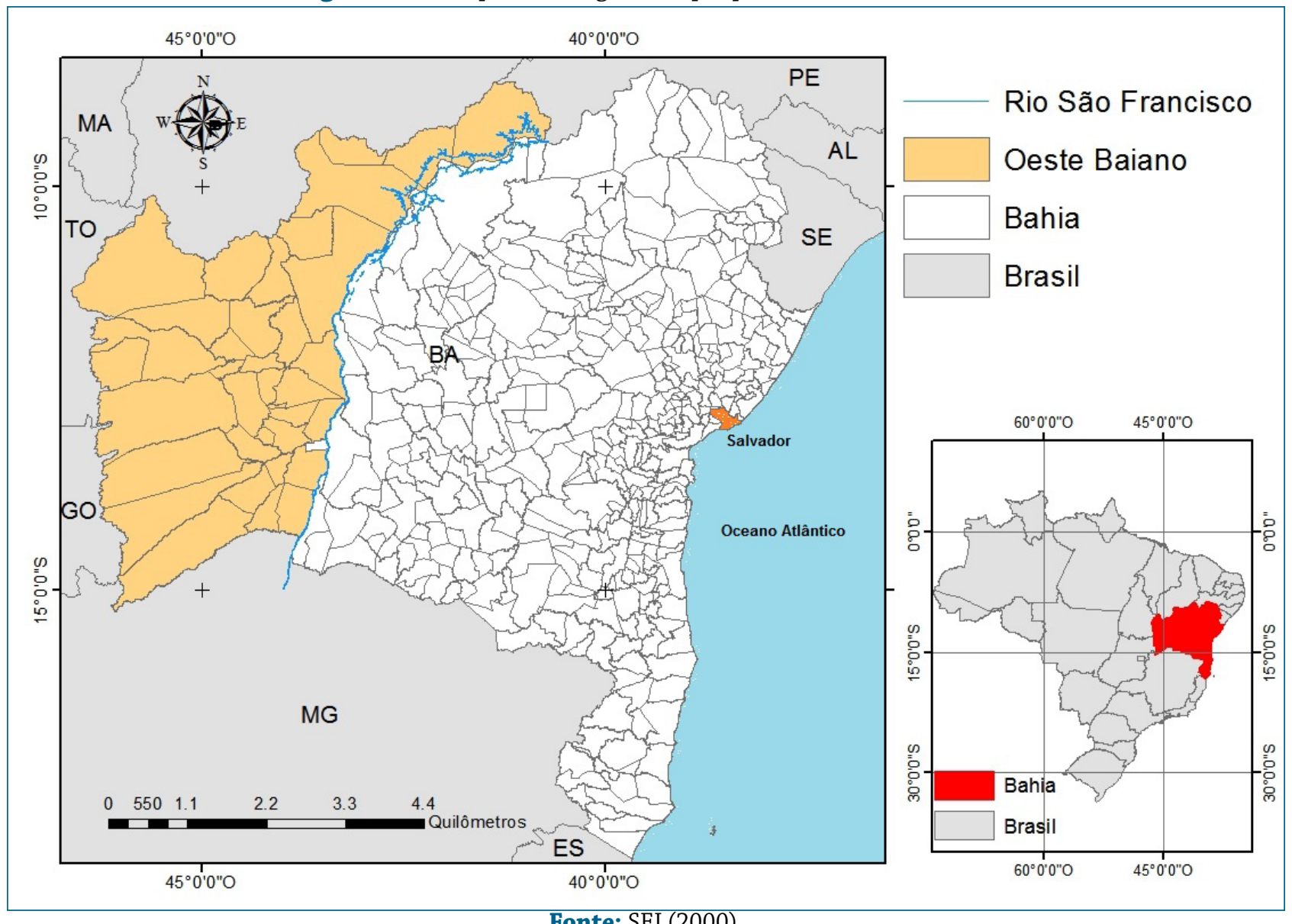

Fonte: SEI (2000).

Elaboração: Maria Aparecida Brito Oliveira.

realizada, tendo a escolha dessas políticas partido, a princípio, dos restritos dados encontrados para o oeste da Bahia, o que demarca certa negligência no acúmulo de informações sobre o território. Este fato se confirma pela dificuldade de encontrar, de forma condensada, as informações nos bancos de dados dos órgãos de governo (estadual e federal). Partindo da ausência de informações, optou-se por selecionar aquelas obras/ações que consideramos mais impactantes ou de maior influência no território. Essas obras/ações compõem as principais políticas territoriais e/ou se apresentam como resultados operativos das políticas de Estado, podendo assim ser definidas como marcos territoriais. Centrou-se na observância de questões de ordem mais técnica (objetos ou formas geográficas) a exemplo de barragens, hidrelétricas e estradas, e nas questões de ordem operativa ou de gestão, demarcando a existência de órgãos ou estruturas administrativas

Quadro 1. Quadro-síntese das principais políticas territoriais adotadas na investigação.

\begin{tabular}{|c|c|c|}
\hline Bloco & Bloco A & Bloco B \\
\hline Tipo & Infraestrutura e/ou redes técnicas & Serviços e/ou redes de gestão \\
\hline $\begin{array}{l}\text { Ações/ } \\
\text { Políticas }\end{array}$ & $\begin{array}{l}\text { Rodovias (federais e estaduais); ferrovias; aeródromos públicos } \\
\text { (aeroportos ou pistas de pouso); barragens, represas e açudes; } \\
\text { perímetros irrigados; centrais de energia elétrica (pequena central } \\
\text { elétrica ou usina hidrelétrica); }\end{array}$ & $\begin{array}{l}\text { Universidades (federais e estaduais); bancos públicos; postos dos } \\
\text { ministérios (ministério do trabalho); órgão do governo (IBGE, INSS); } \\
\text { agências e órgãos estaduais (DIREC, DIRES, Derba, Agerba, Adab, } \\
\text { CAR, Ebda, Sefaz); }\end{array}$ \\
\hline
\end{tabular}

Elaboração: Maria Aparecida Brito Oliveira. 
de governo que têm impacto territorial. Tendo como referência esta divisão, buscou-se categorizar as políticas direcionadas, tanto aquelas de escala federal quanto estadual, localizando os municípios que receberam essas políticas e o período em que foram implementadas.

Cabe destacar que, ao longo da discussão, o território em questão recebeu diferentes denominações, destacando-se Além São Francisco, Oeste da Bahia, Oeste na Bahia, nomenclaturas definidas de acordo com o contexto político territorial e os conteúdos das políticas territoriais específicas. Estas definições podem ser compreendidas como fases para organização das políticas territoriais:

a. Primeira Fase ou Além São Francisco, entre 1889 e 1955;

b. Segunda Fase ou Oeste da Bahia, entre 1956 e 1979; e

c. Terceira Fase ou Oeste na Bahia, entre 1980 e 2014.

As especificidades de cada período, bem como as ações que mais se destacaram serão apontadas nas próximas seções, de modo a caracterizar a formação territorial da porção baiana mais ocidental.

\section{A construção do Além São Francisco e o destaque para as políticas territoriais entre 1889 e 1955.}

Desde a sua ocupação e durante um longo período, toda porção mais a oeste do território baiano - margem esquerda do Rio São Francisco - poderia ser classificada como um imenso fundo territorial, reserva de espaço para futuras intervenções, conforme definição de Moraes (2005). Por esta constatação, as ações em termos de políticas territoriais não se efetivaram significativamente até a segunda metade do século $\mathrm{XX}$, tendo em vista que o território não era foco de grandes investimentos do Estado.

Para compreender como as ações foram se estruturando ao passar do tempo, torna-se fundamental apresentar as escolhas metodológicas para definição dos recortes temporais. Num primeiro momento, Primeira Fase, o marco da formação do chamado Além São Francisco, na perspectiva deste trabalho, foi a Proclamação da República Brasileira em 1889, fato que inaugurou um novo regime administrativo, político, econômico e territorial. O segundo marco temporal, 1955, representa o ano em que se inaugura o planejamento institucionalizado no estado da Bahia, haja vista que até este período não havia condições infra estruturais e/ ou pretensões de ideais políticos em organizar uma outra estrutura de planejamento estatal. Considera-se a segunda metade da década de 1950 como o período de forte debate versando sobre o planejamento estadual, o que se reflete numa mudança de perspectivas acompanhando a própria conjuntura de planejamento a nível nacional.

$\mathrm{Na}$ porção oeste da Bahia, o período em questão, 1889-1955, representou uma mudança na condição de fundo territorial para Além São Francisco. Nos denominados fundos territoriais, ou sertões, a perspectiva de ação era sempre garantida pela apropriação como reserva de espaço para atividades futuras. (MORAES, 2013). Num segundo momento, os objetivos corresponderiam aos novos usos sociais e políticos destes territórios, que, no contexto federativo/republicano, representaram a expansão dos projetos do Estado em direção a essas porções, conforme os aspectos da interiorização, integração nacional, marcha para o oeste, ampliação da fronteira agrícola, que se caracterizam por serem uma "particularidade histórica" no processo de formação territorial brasileira, segundo defende Moraes (2013).

No intervalo temporal apresentado, gradativamente o território foi se tornando estratégico, pelo desenvolvimento de pequenas atividades produtivas, como a pecuária bovina, a agricultura de pequena escala e o extrativismo, o que convém ser caracterizado como catado ${ }^{2}$,

||I|||||||||||||||||||||||||||||||||

2 Entre os produtos da agricultura, destaca-se a produção de mandioca, feijão, milho, arroz e algodão, além da extração de carnaúba e mangabeira. 
conforme aponta Freitas (1999). No entanto, estas atividades não foram suficientes para inseri-lo no contexto econômico estadual e/ou nacional. As razões para esta pouca expressividade podem ser explicadas pelo cenário político em que as elites agroexportadoras na escala nacional e regional estavam envolvidas, especialmente pela mudança de eixo econômico/produtivo do Nordeste para o Sudeste do Brasil ainda no final do século XIX. O açúcar, principal produto nordestino e baiano, foi perdendo prestígio para a nova promessa agrícola, o café produzido no Vale do Paraíba paulista. (OLIVEIRA, 1993).

Os investimentos econômicos e as ações em termos de políticas na Bahia, naquele período, concentravam-se na região decadente da produção açucareira e de fumo no recôncavo, na zona cacaueira do sul e na centralidade administrativa de Salvador. As áreas interioranas do estado baiano, como o chamado sertão, o norte e o oeste, não representavam interesses do ponto de vista econômico, e as medidas eram pontuais se consideradas outras áreas de maior concentração da produção.

A combinação dos aspectos políticos e econômicos ajudou a construir o discurso de isolamento do oeste baiano e a conformação do denominado Além São Francisco, área conhecida e reconhecida pelo Estado e suas lideranças administrativas, apesar de não se apresentar como eixo de grandes investimentos. Trabalha-se com a hipótese de que, em virtude de outras preocupações políticas, da opção econômica do Estado, esta área não se apresentava como potencial para mais investimentos, dadas as características daquela conjuntura e sua "herança" como fundo territorial - espaço para apropriação futura. O “além” estava, portanto, distante, longínquo e isolado, sendo pouco representativo economicamente.

Uma das parcas iniciativas para inserir o recorte no planejamento de políticas foi a criação da Comissão do Vale do São Francisco (CVSF) em 15 de dezembro de 1948, mostrando o explícito interesse de promover o aproveitamento hidroelétrico e implantar projetos de mecanização agrícola em todo vale do Rio São Francisco
(COSTA, 2011). Esta medida estava atrelada ao ideal desenvolvimentista que propunha ações e projetos visando superar os grandes problemas nacionais e inserir o Brasil entre as grandes potências desenvolvidas. Era um momento em que a industrialização se tornara o objetivo principal para o "ideal de crescimento econômico", sendo, para tanto, necessário investir em potencial energético como fora o caso das ações no Vale do Rio São Francisco.

Em termos de ações na escala estadual baiana, a posse do governador Antonio Balbino, em 1955, representou uma possibilidade de novas perspectivas de planejamento. Entre as principais medidas adotadas para toda a Bahia, estava a criação da Comissão de Planejamento Econômico $(\mathrm{CPE})$, voltada para a construção de metas da administração estadual para resolver o problema econômico baiano, mas sem grandes repercussões na porção mais ocidental do estado.

Podem-se citar também como medidas para o Além São Francisco, a expansão da navegação fluvial e do transporte ferroviário, a criação de projetos irrigação, a instalação de agências bancárias e algumas iniciativas de participação privada, como, por exemplo, a navegação desenvolvida desde meados dos anos de 1865 e a construção do aeroporto em Barreiras em 1940. O Quadro 2 sintetiza as principais medidas adotadas nas escalas de planejamento e suas características.

Destaca-se que, na escala de governo estadual, praticamente não houve iniciativas promovidas até os anos 1950, e nem mesmo a eleição de um representante dos oestinos ${ }^{3}$ para o cargo de governador da Bahia foi capaz de facilitar ou destinar novas ações para os municípios da margem ocidental do Rio São Francisco, o que, para Santos (2011), contribuiu para permanecer com a estagnação econômica baiana. O território continuava sem visibilidade para o planejamento do Estado e carente de grandes investimentos. Das informações sintetizadas no Quadro 2, observase que o Além São Francisco não experimentou

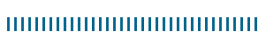

3 No ano de 1955, o barreirense Antonio Balbino foi eleito governador da Bahia. 
Quadro 2. Síntese das Políticas Territoriais e iniciativas privadas voltadas para o Além São Francisco-1889 a 1955.

\begin{tabular}{|c|c|c|c|}
\hline Ação/ política & $\begin{array}{l}\text { Agente/ } \\
\text { Iniciativa }\end{array}$ & Período & Características \\
\hline Navegação* & $\begin{array}{l}\text { Governo } \\
\text { Provincial }\end{array}$ & 1865 & $\begin{array}{l}\text { Governo incentiva a construção de uma embarcação para navegação no Rio São Francisco (o vapor } \\
\text { Conselheiro Dantas) interligando diversos localidades. A navegação oficial ficou parada durante algum } \\
\text { tempo sendo realizada apenas por embarcações particulares. }\end{array}$ \\
\hline Ferrovia & Federal & 1896 & $\begin{array}{l}\text { Governo federal investe em novos ramos e extensão da Ferrovia Bahia - São Francisco ligando Salvador } \\
\text { à Juazeiro. }\end{array}$ \\
\hline Navegação & Privada & 1865 & $\begin{array}{l}\text { Comerciantes locais iniciam a navegação com embarcações próprias entre as pequenas cidades } \\
\text { ribeirinhas, transportando pessoas e mercadorias. }\end{array}$ \\
\hline Aeroporto & Privada & 1940 & $\begin{array}{l}\text { Constrói-se um aeroporto em Barreiras que se torna ponto para reabastecimento de voos de } \\
\text { companhias americanas. Mais tarde figura-se como base militar americana na II Guerra Mundial. }\end{array}$ \\
\hline Agências Bancárias & Federal & 1943 & $\begin{array}{l}\text { Instalação de agências do Banco do Brasil nos municípios de Barra e Barreiras, atendendo as solicitações } \\
\text { da elite local. }\end{array}$ \\
\hline CVSF $^{* *}$ & Federal & 1948 & $\begin{array}{l}\text { Governo Federal inicia trabalho de intervenção na Bacia do Rio São Francisco com projetos de } \\
\text { expansão/irrigação agrícola e construção de hidroelétricas. }\end{array}$ \\
\hline
\end{tabular}

*A navegação pelo Rio São Francisco teve início ainda no Período Imperial e recebeu poucos investimentos na República, decaindo no início do século XX; ${ }^{* *}$ Comissão do Vale do São Francisco (CVSF) criada em 15 de dezembro de 1948. Posteriormente se torna CODEVASF.

Fonte: Pesquisa de Campo (2015); Elaboração: Maria Aparecida Brito Oliveira.

profundas mudanças em sua estruturação. As ações do Bloco A de infraestrutura e/ou redes técnicas podem ser identificadas pela navegação nos rios, construção da ferrovia e da CVSF. Já as ações do Bloco B são sinalizadas apenas pela implantação de agências bancárias. De acordo com as características apresentadas, a projeção do território estava mais restrita a uma expressividade local e/ou regional, sem grande participação no cenário nacional.

Analisando o intervalo temporal de pouco mais de sessenta anos, pode-se considerar que boa parte da extensão territorial foi negligenciada, o que leva a caracterizar uma ausência de políticas territoriais. A não atuação do Estado é compreendida neste trabalho como uma estratégia mesmo que não estritamente planejada, pois, conforme defende Sánchez (1992), a inexistência de políticas territoriais, ou seja, o não planejamento ou uma não política territorial é também uma política, tendo em vista que a partir do momento em que se elegem espaços prioritários para ação, o Estado age como um incentivador do território, promovendo a integração de áreas estratégicas e/ou provocando o desequilíbrio entre outras áreas. Não agindo sobre alguns espaços e atuando fortemente sobre outros, o Estado induz diferentemente o crescimento de porções do território que lhes são oportunas em um dado momento histórico.
Além disso, pelo fato de ser durante muito tempo um imenso fundo territorial, o território em destaque não recebeu grandes projetos ou políticas significativas. Por esses argumentos, este Além São Francisco é caracterizado pela ausência de projetos, de programas e obras de grandes impactos territoriais que justifiquem a própria denominação do território e ratifiquem a visão das políticas territoriais no período avaliado.

\section{Surgimento do Oeste "da" Bahia: os marcos territoriais significativos} entre 1956 e 1979

No Além São Francisco, a partir da segunda metade do século XX, algumas mudanças em termos de políticas foram percebidas. Metodologicamente, recortou-se este período entre 1956 e 1979, buscando evidenciar que ações foram mais significativas nesta Segunda Fase. O primeiro ano (1956) seguinte à posse do governador Antonio Balbino, nascido em Barreiras, portanto um representante dos oestinos, poderia possibilitar maior visibilidade do território do Além São Francisco em termos de políticas territoriais, fato que não se concretizou por completo. O segundo ano (1979) representa a posse do governador Antonio Carlos Magalhães e demarca o ano anterior ao lançamento de 
programas de governos específicos voltados à atuação agrícola na porção ocidental baiana.

Neste período, as principais propostas foram destinadas especialmente à escala federal, enquanto na escala estadual, embora muitos esforços tivessem sido enviados para a estruturação econômica baiana, as medidas continuaram concentradas em poucas áreas. A política cacaueira, a exploração do Petróleo e a modernização industrial da Bahia exemplificam os investimentos neste período (SANTOS, 2007), acompanhando uma tendência nacional. De modo geral, as ações foram pontuais e privilegiaram setores específicos, atendendo os desejos das elites locais/regionais como evidenciado em todo o período desenvolvimentista em meados da década de 1950 e que Becker e Egler (2011) sinalizam como período de uma modernização conservadora, centrada na industrialização, no ritmo rápido de crescimento e no controle e autoritarismo político.

É somente a partir de 1970, acompanhando o conjunto de propostas definidas para ocupar todo o interior do território nacional e ampliar a fronteira agrícola nos cerrados, que novas estratégias foram direcionadas. Em virtude de uma extensa área de ocorrência deste domínio natural na Bahia, os governos investiram em projetos de expansão da agricultura mecanizada e, desde então, o Além São Francisco passou a ser reconhecido como local estratégico de investimentos. Kraychete e Comerford (2012) afirma que,

A partir da década de 1970, o Oeste baiano vem sendo palco de um intenso e rápido processo de transformações, provocando um abrupto contraste com o estado de letargia secular que caracterizava a economia e a sociedade locais. A expansão da moderna agricultura em direção ao Centro-Oeste e ao Vale do São Francisco resulta num rápido processo de diferenciação social, reproduzindo regionalmente estruturas características da sociabilidade vinculada aos agentes presentes na agricultura capitalista. Serão, sobretudo, personagens extralocais que aparecerão como portadores das transformações da região: gaúchos e japoneses em Barreiras, fazendeiros pernambucanos e de outras regiões em Santa Maria da Vitória, órgãos do governo e empresas privadas nos projetos de irrigação. (KRAYCHETE; COMERFORD, 2012, p. 98-99).
Após este contexto apresentados pelos autores citados, a nomenclatura Além São Francisco pode ser substituída por Oeste da Bahia. Este “oeste”, que se estrutura entre 1956 e 1979, apresenta mudanças de ordem técnica, social, econômica e política com a rápida expansão da agricultura mecanizada e a consolidação do agronegócio como marca predominante, voltadas para a cultura da soja em grande escala. Inúmeros estudos e programas foram desenvolvidos por órgãos governamentais como a Empresa Brasileira de Pesquisa Agropecuária - EMBRAPA, reafirmando a viabilidade produtiva dos cerrados e atraindo investimentos públicos e privados para esta área (SANTOS, 2007). Podem-se citar o Programa de Desenvolvimento dos Cerrados - POLOCENTRO e o Programa de Cooperação Nipo-Brasileira de Desenvolvimento do Cerrado - PRODECER como exemplos de investimentos governamentais pósdécada de 1970, cujos objetivos foram atrelados às políticas de crescimento regionais e expansão da fronteira agrícola nos cerrados. Estes programas coadunam com a opção de desenvolvimento agrário brasileiro, que foi direcionado para os "espaços vazios ainda possíveis de serem ocupados" - os fundos territoriais. Esta definição converge com a defesa de Moraes (2005), quando o autor destaca os antigos fundos territoriais como porções estratégicas para expansão de atividades no território. Outrora estes espaços se impunham como expressão da ocupação/ conquista colonial, hodiernamente se tornaram os lugares privilegiados para a implantação de políticas territoriais específicas do Estado. O Oeste da Bahia e toda a área dos cerrados brasileiros representaram, num período mais recente, a expressão concreta deste movimento, cujas transformações foram viabilizadas pela atuação massiva do Estado, mas que não trouxeram reflexos tão positivos para sociedade e para a grande maioria da população local.

Entre as principais medidas que atingiram especificamente o Oeste da Bahia destaca-se a construção/inauguração de Brasília, ainda na década de 1960, sendo a nova capital geograficamente situada num espaço de grandes 
"promessas econômicas" - o cerrado brasileiro. Para viabilização da nova sede administrativa e política do país, incentivou-se a abertura de estradas, de redes de transportes e de comunicação, que, de modo indireto, beneficiaram alguns municípios do território oestino, impulsionando mais tarde o desenvolvimento da cultura de soja para exportação. (SANTOS FILHO, 1989).

Acompanhadas da construção da capital, a abertura de vias federais importantes como as BRs 242, 135 e 020, diretamente associadas aos planos de infraestrutura da época, permitiu a conexão entre diferentes pontos do território, contudo não foram suficientes para romper, por completo, o isolamento geográfico do Oeste da Bahia, pela insuficiência do número destas vias de acesso e pela imensidão territorial. Uma consequência negativa da instalação destes objetos geográficos foi a decadência do antigo sistema hidroviário historicamente predominante. A navegação foi gradativamente perdendo prestígio pela ampliação do sistema rodoviário e pelos novos usos atribuídos aos rios da Bacia do São Francisco (irrigação e hidroeletricidade).

O Quadro 3 reúne as ações prioritárias implantadas no território. Cabe destacar a existência de uma lacuna, tanto no que diz respeito à discussão das políticas territoriais nesta porção da Bahia, quanto à consolidação de documentos oficiais de governo. Neste sentido, as informações contidas são fruto de um vasto trabalho de pesquisa que permitiu selecionar e compilar as principais informações disponíveis em diferentes bancos de dados.

O Quadro 3 mostra a predominância nas ações de escala federal, e as políticas identificadas estão diretamente relacionadas à expansão do projeto desenvolvimentista brasileiro, como a construção de Brasília, a abertura das estradas e as ações no vale do São Francisco, tendendo à utilização do potencial do rio para a agricultura (perímetros irrigados) e para a hidroeletricidade (barragem de Sobradinho). Inexpressiva foi a participação estadual em termos de projetos, apontando a negligência na elaboração de políticas. O Programa de Recuperação Econômica da Bahia, lançado pelo grupo da CPE no ano de 1958, o Plano de Desenvolvimento da Bahia (1960-1963) e o Programa de Desenvolvimento Regional do Além São Francisco (1979-1982) representam as poucas iniciativas a nível estadual, mas sem definir grandes impactos ou marcos para o oeste. (BAHIA, 1979). Além disso, apenas este último programa tinha um foco mais específico para o recorte, mantendo a denominação antiga de Além São Francisco. Estes dados permitem considerar que a participação dos governos da Bahia foi mais efetiva no tocante às pesquisas científicas e investimentos em programas que fomentaram as condições viáveis de incentivo as novas políticas no oeste, consolidadas somente na década de

Quadro 3. Síntese das Políticas Territoriais voltadas para o Oeste da Bahia-1956-1979.

\begin{tabular}{|c|c|c|c|}
\hline $\begin{array}{l}\text { Ação/ } \\
\text { Política }\end{array}$ & $\begin{array}{l}\text { Agente/ } \\
\text { Iniciativa }\end{array}$ & Período & Características \\
\hline Inauguração de Brasília & Federal & 1960 & $\begin{array}{l}\text { Além da construção da nova capital o conjunto de infraestrutura criada para ampliar o acesso ao } \\
\text { interior do país viabilizaram modificações territoriais nos municípios do raio de influência de Brasília. }\end{array}$ \\
\hline $\begin{array}{l}\text { Hidrelétrica de } \\
\text { Correntina }\end{array}$ & Federal & 1966 & Construção da hidrelétrica visando o abastecimento energético da região. \\
\hline $\begin{array}{l}\text { Construção da BR 242, } \\
\text { BR } 020 \text { e BR } 135\end{array}$ & Federal & 1969 & $\begin{array}{l}\text { Construção da Rodovia Salvador - Brasília e demais vias federais e Instalação do } 4^{\circ} \text { Batalhão de } \\
\text { Engenharia e Construção - BEC, na cidade de Barreiras. }\end{array}$ \\
\hline Barragem de Sobradinho & o Federal & 1977 & $\begin{array}{l}\text { Construída pela CHESF (Companhia Hidroelétrica do São Francisco). A barragem possui área total } \\
4214 \mathrm{~km}^{2} \text { abrangendo os municípios de Casa Nova, Pilão Arcado, Remanso, Sento Sé, Sobradinho e } \\
\text { Juazeiro, com a finalidade de geração de energia elétrica. }\end{array}$ \\
\hline Perímetros Irrigados & Federal & 1978 & $\begin{array}{l}\text { Viabilização de projetos de irrigação pública nos municípios de Barreiras, São Desidério e Coribe } \\
\text { incentivados pela Codevasf (Companhia de Desenvolvimento dos Vales do São Francisco e do Parnaíba. }\end{array}$ \\
\hline Agências Bancárias & $\begin{array}{l}\text { Federal/ } \\
\text { Estadual }\end{array}$ & - & $\begin{array}{l}\text { Instalação de agências de bancos públicos nos municípios de Barreiras, Carinhanha, Casa Nova, } \\
\text { Correntina, Cotegipe, Formosa do Rio Preto, Remanso, Riachão das Neves, Santa Maria da Vitória, } \\
\text { Santa Rita de Cássia, Santana e Wanderley. }\end{array}$ \\
\hline
\end{tabular}

Fonte: Pesquisa de Campo (2015); Elaboração: Maria Aparecida Brito Oliveira. 
1980. Pelas ações destacadas e sintetizadas no Quadro 3, nota-se que todas compõem o Bloco A, compreendendo as infraestruturas e/ou redes técnicas, com exceção das agências bancárias, estas incluídas no Bloco B de serviços e/ou as redes de gestão.

Resumidamente, é possível identificar que na Segunda Fase, entre 1956 e 1979, as medidas prioritárias, consolidaram as bases para implantação de novos projetos e ações destinado ao oeste. Neste período, experimenta-se uma mudança de projeção do território, de uma escala local/regional para a regional/nacional, devido as especificidades das políticas adotadas.

\section{Construção de um Novo Oeste? A "modernização" do território e a conformação do Oeste "na" Bahia a partir da década de 1980.}

Após a introdução da agricultura de grãos nos cerrados baianos, algumas mudanças em múltiplas dimensões (políticas, econômicas, sociais) foram percebidas nos municípios do oeste. O marco inicial para este período, Terceira Fase, é representado pelo ano de 1980, em que programas governamentais na Bahia passaram a priorizar novas estratégias de intervenção. A etapa se estende até 2014, período recortado para esta pesquisa.

As políticas territoriais destinadas assumiram um padrão diferente dos contextos anteriores, permitindo a inserção do território na economia estadual, nacional e mundial, porém sem possibilitar as transformações dos aspectos sociais para toda a população. No Oeste da Bahia, o Estado foi um dos grandes responsáveis pela criação da infraestrutura, permitindo desde as pesquisas científicas e tecnologia de ponta, até o incentivo à atração de capitais nacionais e internacionais. (SANTOS, 2007). Uma nova forma de produção globalizada ganhou tônica no oeste, antes reserva territorial (fundos territoriais), provocando uma rápida ocupação do território e uma visibilidade maior nos planos de governos em suas diferentes escalas (federal e estadual). Segundo Kraychete e Comerford (2012), a articulação entre Estado e investidores privados foi um fator essencial para as mudanças.

O Estado desempenhou um importante papel como agente viabilizador deste processo, fornecendo apoio financeiro, implantando uma infraestrutura física e institucional ou mesmo fazendo "vista grossa" às apropriações ilegais de terras e outras violências contra os camponeses. Favorecida pela atuação do Estado, a iniciativa privada passa a exercer o seu "pioneirismo", promovendo a "ocupação do Oeste", que conduz à moderna agricultura que se expande na região [...] A intervenção estatal na região também está associada aos interesses envolvidos na ocupação dos cerrados brasileiros, onde estão presentes empresas, cooperativas e o governo japonês, que participa técnica e financeiramente do Prodecer através do JICA (Japan Internacional Cooperation Agency). (KRAYCHETE; COMERFORD, 2012, p. 99-100).

Já de acordo com Santos (2007), é no início da década de 80, com o lançamento o Programa de Ocupação Econômica do Oeste - Programa Básico, que o território passou a receber maior atenção estadual com foco em diferentes atividades como o desenvolvimento da navegação no Rio São Francisco, a articulação viária, investimentos em centros urbanos, desenvolvimento agropecuário, entre outros aspectos, conforme dados do próprio documento (BAHIA, 1980c). De modo geral, as ações visavam criar condições para a expansão econômica especialmente do oeste, aproveitando o potencial já explorado por projetos privados, instalados anteriormente. Também Silva, Leão e Silva (1989) ratificam esta questão, ao sinalizar que esta década foi o marco indicador das transformações regionais, sendo que, a partir de então, o oeste passa a receber atenção do governo estadual com a criação do referido programa. As transformações se intensificaram no início do século XXI, pela crescente demanda de capital e emergência do recorte no cenário internacional.

Outro documento produzido pelo governo baiano na década de 1980 foi o "Levantamento das Necessidades de Investimentos Públicos na Região Oeste da Bahia", que, integrando a proposta de ocupação econômica, visava apontar as áreas e os aspectos para "incorporar" economicamente este recorte à economia da Bahia. Não se trata de um programa ou política, mas de um documento 
elaborado pela Fundação Centro de Pesquisas e Estudos - $\mathrm{CPE}^{4}$, junto à Secretaria de Planejamento, Ciência e Tecnologia - SEPLANTEC, como requisito para organizar as ações do Programa de Ocupação Econômica do Oeste.

Outras medidas priorizaram diretamente o território, como o Programa de Desenvolvimento do Oeste Baiano - PRO-OESTE, lançado em 1987, e o documento intitulado "Era uma vez o Oeste. A modernização da fronteira agrícola na Bahia", produzido pela SEPLANTEC em 1988, que ficou conhecido como Carta da $\mathrm{CPE}$, cujo conteúdo apresentava as transformações ocorridas pós anos de 1970. Entre as questões centrais pontuadas, estão a emergência do oeste para uma escala nacional/global, a rápida penetração de capital do agronegócio, a expansão da produção de grãos, a migração de sulistas e japoneses e as transformações ocorridas nos municípios. $\mathrm{O}$ referido documento aponta as contradições que o processo modernizador trouxe: por um lado, elevando o Produto Interno Bruto - PIB e os recursos técnicos e econômicos nos municípios; por outro, acentuando a pobreza e segregando as populações mais carentes. Deste modo, o ritmo de crescimento não veio acompanhado de desenvolvimento social, intensificando os graves problemas existentes e criando novas problemáticas sociais, ratificando que os investimentos foram selecionados para uma delimitação específica do oeste.

Muitos outros documentos foram produzidos pela equipe técnica dos governos visando propor ações, projetos e programas para o Oeste da Bahia, contudo, foram elencados apenas aqueles documentos cujas características resumem o quadro político/econômico pelo qual atravessou o território na fase mais recente de sua formação territorial. O que se nota é que, durante muito tempo, pouco se discutiu a respeito de medidas voltadas para este recorte territorial, fato comprovado pela inexistência de registros mais específicos até o início da década de 1980. A partir deste período, há um reconhecimento das

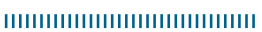

4 A CPE, quando foi criada na década de 1950, denominava-se Comissão de Planejamento Econômico. potencialidades do território e da viabilidade econômica para sua exploração. Entretanto, os documentos produzidos foram centralizados num conjunto de ações voltadas para a expansão da infraestrutura do agronegócio de grãos e, apesar do esforço de algumas pesquisas, pouco se discutiu sobre o contexto geral do Oeste da Bahia, indicando que a literatura não é tão vasta, e os documentos apresentam, muitas vezes, argumentos ambíguos. (CARIBÉ; VALE, 2012). Por essas questões, é possível retornar as discussões de Sánchez (1992), quando afirma que

En la práctica, solo las relaciones de poder de cada momento darán la respuesta real a las diversas aspiraciones y deseos proyectados sobre um território. La historia, no es la historia de las ideias y de las aspiraciones, sino del domínio resultante de cada relación de poder concreta. (SÁNCHEZ, 1992, p. 38)

Nessa direção, o conjunto de ações, de perspectivas e políticas aplicadas ao oeste foi resultante do jogo de forças sobre o território. Se em um dado momento a ação do Estado não demonstrava interesse, esta posição se alterava na medida em que novos elementos emergiam no processo de constituição/formação territorial.

Do ponto de vista operativo, os marcos territoriais mais concretos para o período estão sintetizados no Quadro 4, que evidencia o conjunto de medidas atreladas à infra estruturação do oeste após investimentos na modernização agrícola.

O maior número das políticas (programas, projetos, obras e ações), ou seja, os principais marcos territoriais e/ou objetos geográficos foram se situando em municípios específicos como Barreiras, Santa Maria da Vitória, São Desidério e Luis Eduardo Magalhães, enquanto municípios como Baianópolis, Canápolis, Cotegipe, Feira da Mata, Mansidão e demais receberam pouquíssimas ações entre 1980 e 2014. O Gráfico 1 ajuda a compreender esta questão ao enumerar o volume de políticas desde 1950. É possível extrair das informações reunidas no Gráfico 1 que, de um total de 35 municípios, apenas 14 apresentaram acima de dez políticas territoriais. Além disso, dez destes municípios não chegaram a ultrapassar 
Quadro 4. Síntese das Políticas Territoriais voltadas para o Oeste na Bahia- 1980-2014.

\begin{tabular}{|c|c|c|c|}
\hline $\begin{array}{l}\text { Ação/ } \\
\text { Política }\end{array}$ & Agente & Período & Características \\
\hline $\begin{array}{l}\text { Usinas eólicas, } \\
\text { termelétricas e/ } \\
\text { ou hidrelétricas. }\end{array}$ & Federal & A Partir de 1980 & $\begin{array}{l}\text { Implantação de sistemas de energias, gerando a força motriz necessária para viabilizar a } \\
\text { instalação de indústrias (agroindústrias) e maquinário. Apenas os municípios de Barreiras, } \\
\text { Casa Nova, Correntina, Formosa do Rio Preto, Jaborandi, Santana e São Desidério foram } \\
\text { contemplados com o total de } 15 \text { ações. }\end{array}$ \\
\hline $\begin{array}{l}\text { Projetos de } \\
\text { irrigação }\end{array}$ & Codevasf & 1998 e 1999 & $\begin{array}{l}\text { Instalação dos Projetos de Irrigação de Riacho Grande/Nupeba e Barreiras Norte, } \\
\text { contemplando apenas os municípios de Riachão das Neves e Barreiras. }\end{array}$ \\
\hline $\begin{array}{l}\text { Barragens, } \\
\text { açudes e } \\
\text { represas. }\end{array}$ & $\begin{array}{c}\text { Codevasf e } \\
\text { CERB* }\end{array}$ & Entre 1980 e 2000 & $\begin{array}{l}\text { Destinação de } 84 \text { ações nos municípios do oeste. As obras tinham principalmente } \\
\text { a finalidade de abastecimento e irrigação. Do total de } 35 \text { municípios, Baianópolis, } \\
\text { Carinhanha, Cotegipe, Cristópolis, Feira da Mata, Luis Eduardo Magalhães, Muquém } \\
\text { do São Francisco, Pilão Arcado, Santa Rita de Cássia, Sítio do Mato e Wanderley não } \\
\text { receberam nenhum destes objetos geográficos. }\end{array}$ \\
\hline $\begin{array}{l}\text { Rodovias } \\
\text { federais e } \\
\text { estaduais }\end{array}$ & $\begin{array}{l}\text { Federal e } \\
\text { Estadual }\end{array}$ & A partir de 1980 & $\begin{array}{l}\text { Abertura de acessos rodoviários federais e estaduais no oeste. Dos } 35 \text { municípios apenas } \\
\text { Barra, Brejolândia, Canápolis, Catolândia, Serra Dourada e Wanderley não são diretamente } \\
\text { cortados por rodovias federais enquanto que Campo Alegre de Lourdes, Correntina e } \\
\text { Jaborandi não dispõe de rodovias estaduais pavimentadas. }\end{array}$ \\
\hline $\begin{array}{l}\text { Aeródromos } \\
\text { públicos }\end{array}$ & Estadual & A partir de 1980 & $\begin{array}{l}\text { Abertura de aeródromos públicos em pelo menos } 16 \text { dos } 35 \text { municípios sendo eles, Barra, } \\
\text { Barreiras Buritirama, Campo Alegre de Lourdes, Carinhanha, Casa Nova, Cocos, Coribe, } \\
\text { Correntina, Formosa do Rio Preto, Luis Eduardo Magalhães, Pilão Arcado e Remanso, } \\
\text { Santa Maria da Vitória, Santana, Santa Rita de Cássia. }\end{array}$ \\
\hline $\begin{array}{l}\text { Instituições de } \\
\text { ensino superior }\end{array}$ & $\begin{array}{l}\text { Estadual e } \\
\text { Federal }\end{array}$ & 1987 e 2006 & $\begin{array}{l}\text { Abertura de campus da UNEB (Universidade do Estado da Bahia)na cidade de Barreiras } \\
\text { ainda no ano de } 1980 \text { e em } 2006 \text { do campus da UFBA (Universidade Federal da Bahia, } \\
\text { hoje UFOB (Universidade Federal do Oeste da Bahia). Desde } 2013 \text { novos campus da UFOB } \\
\text { foram abertos em Barra, Luis Eduardo Magalhães e Santa Maria da Vitória. }\end{array}$ \\
\hline $\begin{array}{l}\text { Instalação de } \\
\text { agências de } \\
\text { bancos públicos }\end{array}$ & $\begin{array}{l}\text { Estadual e } \\
\text { Federal }\end{array}$ & A partir de 1980 & $\begin{array}{l}\text { Abertura de pelo menos } 50 \text { agências bancárias, que foram localizadas em } 24 \text { municípios. } \\
\text { Do total de } 35 \text { municípios, } 7 \text { não receberam nenhuma agência pública sendo eles: } \\
\text { Brejolândia, Canápolis, Feira da Mata, Jaborandi, Muquém do São Francisco, São Felix } \\
\text { do Coribe e Sítio do Mato. }\end{array}$ \\
\hline $\begin{array}{l}\text { Instalação de } \\
\text { agências de } \\
\text { gestão federal }\end{array}$ & Federal & A partir de 1980 & $\begin{array}{l}\text { Instalação de agências do IBGE, INSS, TRT, Receita Federal e Justiça Federal localizadas } \\
\text { em Barra, Barreiras, Campo Alegre de Lourdes, Carinhanha, Correntina, Formosa do } \\
\text { Rio Preto, Remanso, Riachão das Neves, Santa Maria da Vitória, Santana, Santa Rita, } \\
\text { São Desidério, São Félix e Serra do Ramalho. }\end{array}$ \\
\hline $\begin{array}{l}\text { Instalação de } \\
\text { agências de } \\
\text { gestão estadual }\end{array}$ & Estadual & A partir de 1980 & $\begin{array}{l}\text { Instalação de agências estaduais, ADAB, AGERBA, DERBA, EBDA, DETRAN, CAR, } \\
\text { SEFAZ, DIREC, DIRES, CERB }{ }^{9} \text {, localizados em } 17 \text { dos } 35 \text { municípios. Sendo: Angical, } \\
\text { Baianópolis, Barreiras, Casa Nova, Cocos, Coribe, Correntina, Cristópolis, Formosa do } \\
\text { Rio Preto, Jaborandi, Luís Eduardo Magalhães, Muquém de São Francisco, Santa Maria } \\
\text { da Vitória, Santana, Santa Rira de Cássia, São Félix do Coribe e Wanderley. }\end{array}$ \\
\hline
\end{tabular}

*Agência Estadual de Defesa Agropecuária da Bahia-ADAB, Agência Estadual de Regulação de Serviços Públicos de Energia, Transportes e Comunicações da Bahia-AGERBA, Departamento de Infraestrutura de Transporte da Bahia-DERBA, Empresa Baiana de Desenvolvimento-EBDA, Departamento Estadual de Trânsito da Bahia-DETRAN, Companhia de Desenvolvimento e Ação Regional-CAR, Secretaria da Fazenda do Estado da Bahia-SEFAZ, Diretoria Regional de Educação-DIREC, Diretoria Regional de Saúde-DIRES.

Fonte: Pesquisa de Campo (2015); Elaboração: Maria Aparecida Brito Oliveira.

cinco ações do total de políticas investigadas neste trabalho. Importante frisar que as unidades administrativas que mais concentraram investimentos foram aquelas geograficamente situadas na parte mais ocidental, conformando a área dos cerrados e ratificando que a maioria dos recursos governamentais dirigidos ao território pós-1980 se concentrou naqueles territórios, cuja expansão do capital, do agronegócio foi mais evidente. As exceções são Casa Nova e Remanso, municípios que não estão inseridos no domínio do cerrado, mas que também se tornaram espaços estratégicos para investimentos em fruticultura irrigada no vale do Rio São Francisco.

Levando em conta o período de mais seis décadas (1950-2014) e a quantidade de municípios (35 ao todo), chega-se ao volume total de 369 ações, projetos e políticas. Apesar do número parecer considerável ele não é tão representativo pela quantidade de anos e número de municípios. 


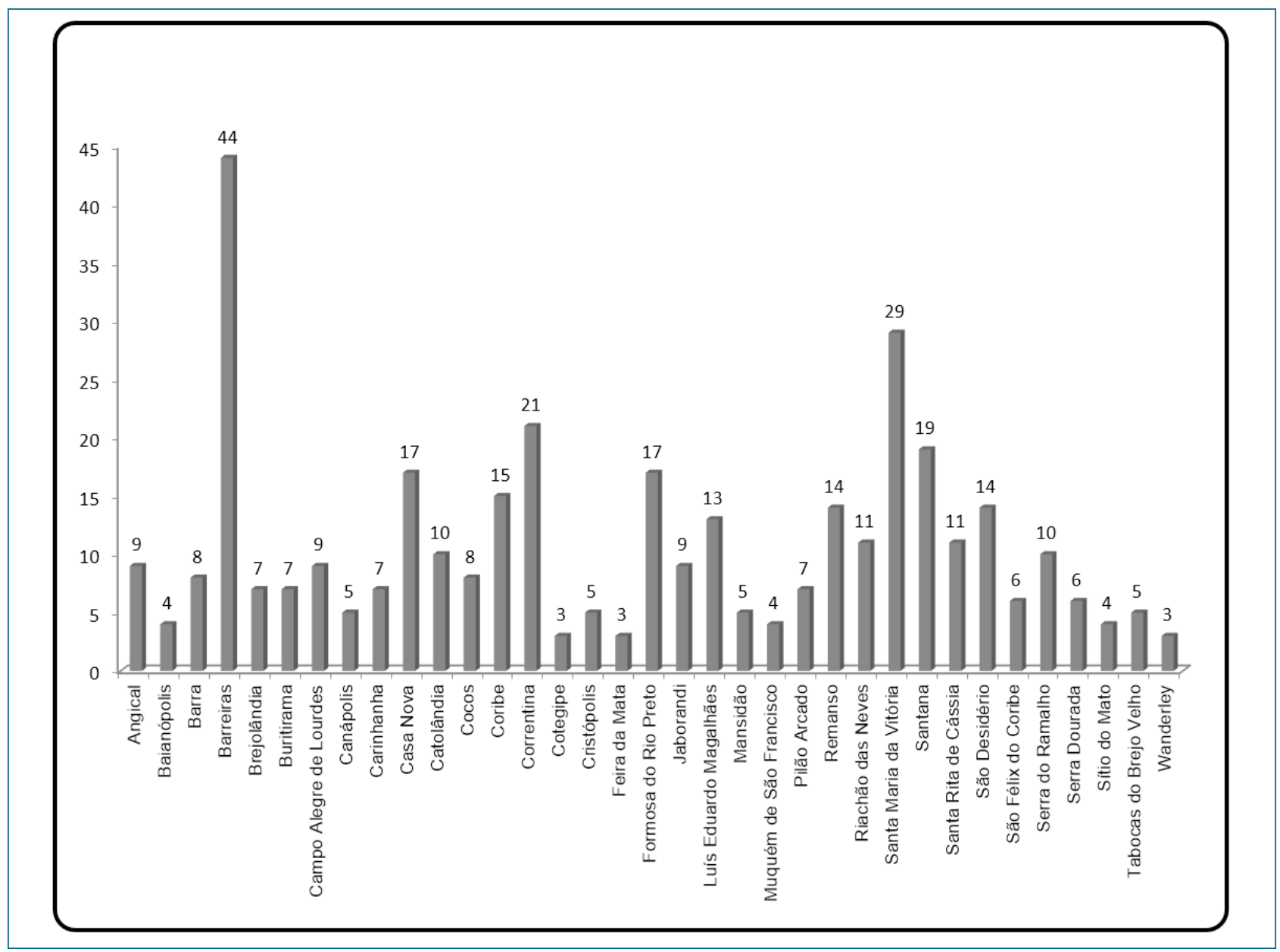

Fonte: Pesquisa de Campo (2014); Elaboração: Maria Aparecida Brito Oliveira.

Se dividirmos as 369 ações no recorte de 64 anos, não se chega a 6 ações/ano destinadas aos 35 entes federativos. Se o cálculo for feito pela quantidade de unidades administrativas de forma igualitária, teríamos pelo menos dez ações para cada entidade ao longo dos 64 anos, entretanto municípios como Cotegipe, Feira da Mata e Wanderley não ultrapassaram três ações ao longo do período. Esta situação poderia levar a reconhecer que existem municípios na porção mais ocidental do território baiano que realmente estão ausentes de políticas territoriais de grande impacto, levando a confirmar, neste sentido, que ainda há um distanciamento do Estado em termos de políticas em grande parte do oeste.

$\mathrm{Na}$ medida em que a agricultura moderna, mecanizada e com ênfase no agronegócio foi se expandindo no Oeste da Bahia, selecionando áreas mais propícias e concentrando os investimentos em poucos municípios, o restante do território não mudou significativamente, permanecendo à margem do processo e ausente de políticas territoriais. As transformações pontuais fazem classificar de uma outra maneira o território, chegando à definição de um Oeste NA Bahia. A mudança de termos "da" e "na" Bahia não representa uma simples troca de preposição, mas indica que, nos últimos anos, uma seletividade específica contribuiu para diferenciar alguns poucos municípios do recorte territorial.

As áreas de maior ocorrência de políticas se impõem como espaços seletivos cujos objetos técnicos artificializados foram implantados de maneira mais expressiva. Por essa razão, o território passa a ser denominado de Oeste na Bahia, sinônimo de um "novo oeste", altamente rentável, seletivo e economicamente produtivo, ao tempo em que é extremamente díspar, 
concentrado e segregado. Este "novo", por sua vez, traz uma nova dinâmica econômica sem inserir todos, ou pelo menos a maior parte dos municípios do oeste, caracterizado que não é uma dinâmica experimentada pela totalidade do território, mas por uma pequena parcela que se destaca "na" Bahia.

O novo direcionamento no oeste se aplica tanto na interpretação de Moraes (2003b; 2005; 2011b), que defende a existência de grandes espaços para "exploração futura" - os fundos territoriais - na trajetória de formação territorial brasileira, quanto na interpretação de Sánchez (1992), que argumenta que, a depender dos interesses do Estado e da conjuntura do momento, um território pode ou não receber incentivos em termos de políticas territoriais, como já sinalizamos anteriormente. Confluindo estas duas interpretações, observase que, a partir de um "novo olhar" do Estado, na porção mais ocidental baiana, e dos novos propósitos de políticas territoriais, a tendência de projetos, programas, obras e ações incorporaram os espaços dos cerrados, uma das últimas fronteiras brasileiras de ocupação econômica. Neste sentido, parte do território, ou um Oeste na Bahia, emergiu de uma escala regional/nacional para uma projeção nacional/internacional pelo conjunto de mudanças operadas neste período. A Figura 2 resume a formação territorial do oeste baiano, destacando os períodos e as características de cada fase e permite sintetizar a análise mais geral deste processo.

A chegada da "moderna agricultura" na área mais ocidental baiana tendeu a romper com o isolamento outrora atribuído, primeiramente ao sertão (fundo territorial), depois ao Além São Francisco e agora ao Oeste da Bahia. Se esta área foi historicamente marginalizada, fato reconhecido pela ausência de políticas territoriais do Estado, a partir da década de 1970, mais especificamente

Figura 2. Formação Territorial do oeste baiano - 1889 - 2014.

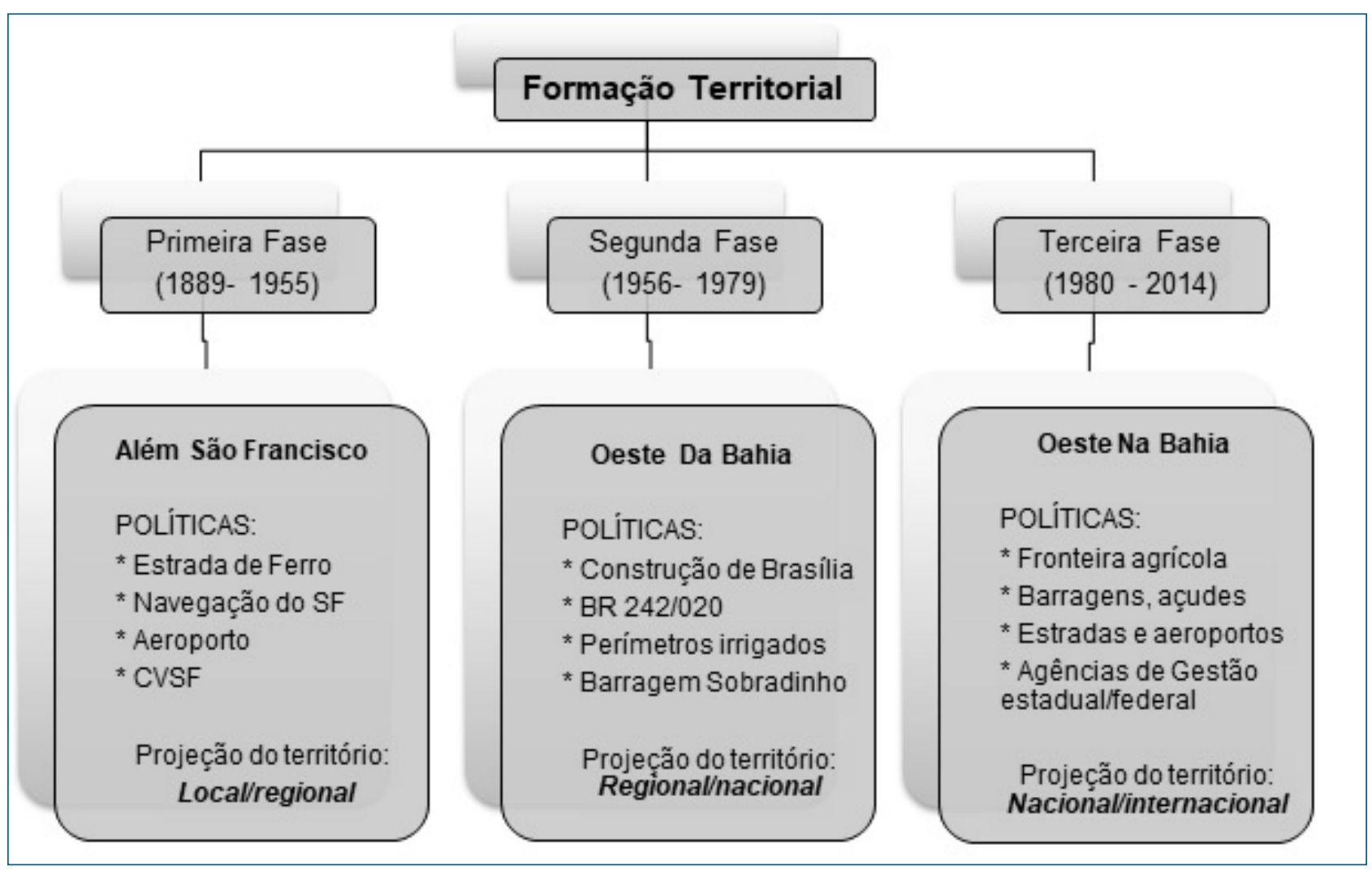

Elaboração: Maria Aparecida Brito Oliveira. 
em meados de 1980, ela se insere, de maneira rápida, numa nova dinâmica econômica. A própria denominação de Oeste na Bahia é um indicativo geográfico, político e econômico para estas mudanças, afinal, não foi qualquer espaço baiano que experimentou tão velozmente mudanças na estrutura econômica, mas, especificamente, a área conformada pelos cerrados, localizada na porção mais ocidental do estado. Entretanto, as mudanças de ordem técnica, econômica, política e territorial vieram acompanhadas de problemas sociais, de uso da terra, de condições de trabalho, enfim, de toda uma dinâmica de sociedade, fruto de um modelo agrícola desenvolvido em todo o país, que priorizou a aceleração do crescimento, sem muita preocupação com os efeitos sociais.

\section{Considerações Finais}

Analisando o processo de formação territorial da margem esquerda são franciscana até a década de 1970, considera-se que este era um espaço invisibilizado em termos de ações e políticas territoriais do Estado, inserindo-se numa proposta política de crescimento econômico através de medidas pontuais e localizadas. Aproveitou-se os aspectos físicos e a disponibilidade de terras para aplicabilidade de projetos de expansão de capital, voltados para o agronegócio, e as ações estiveram diretamente ligadas à expansão das atividades agrícolas modernas neste território.

Estrategicamente, os governos baianos se apossaram das vantagens peculiares do território e acabaram por inseri-lo no escopo do planejamento estatal, tendendo a uma concentração de investimentos para viabilizar a expansão e os ganhos de capital. Ao longo da formação territorial, a virada das décadas de 1970 para 1980 parece ter representado o momento crucial para as ações de governo, potencializando os investimentos e atraindo a atenção de investidores estrangeiros. A partir daí, consolida-se uma nova tendência, cujos reflexos vão acentuar, por um lado, os ganhos econômicos e efetivos de políticas territoriais para uma parte do recorte, e por outro, ampliar a concentração de grandes problemas sociais.
Relacionando o oeste baiano com o histórico brasileiro, observa-se que ambos os processos têm semelhanças e estão bastante articulados. No cenário nacional, a gama de ações desenvolvidas, especialmente em termos de políticas territoriais, assumiu, historicamente, um viés centralista e verticalizado, cujas marcas repercutiram diretamente no espaço, o que, para Becker e Egler (2011), foi fruto do controle político e do projeto nacional autoritário assumido no Brasil. No oeste baiano, estas mesmas características foram percebidas, caracterizando um longo período de negligência do Estado em termos de ações e, mais recentemente, um forte conteúdo de intervenção estratégica, em função da implantação da modernização da agricultura de soja nos cerrados.

A ausência de políticas justifica um tipo especifico de ação, marcada pelo não fazer, que de todo modo também impacta em desdobramentos territoriais. A opção do Estado em não prover ações no oeste baiano pode ser considerada uma opção política que ratifica a trajetória de organização das elites econômicas, do mesmo modo que explica a condição histórica de ser considerado um imenso fundo territorial.

A projeção do território em diferentes escalas, ao longo da formação, ajuda a compreender como as políticas foram importantes para sua estruturação territorial. Do Além São Francisco, cuja perspectiva era mais local/regional, passando pelo Oeste da Bahia, que ganha uma projeção regional/nacional a partir da segunda metade do século XX, até a constituição do Oeste na Bahia, cuja projeção nacional/internacional se consolida após os anos de 1980, o território foi se diferenciando. Reconhce-se que as ações em termos de obras e projetos foram importantes para alterar a dinâmica territorial em seus aspectos políticos e econômicos, contudo, questiona-se o modo concentrado e seletivo como as políticas se efetivaram, não criando condições para os entes que compõem o recorte territorial. Acredita-se que uma redefinição de políticas territoriais só poderá ser alcançada se novos sujeitos forem inseridos no planejamento e gestão das ações, vislumbrando 
mudanças mais efetivas para todo o conjunto territorial do oeste baiano. Cabe, neste sentido, uma nova postura do Estado, em suas diversas escalas de governo, para um repensar das políticas e uma abertura para que a sociedade, entidades particulares e escalas governos construam um novo conteúdo de políticas territoriais.

\section{Referências}

BAHIA. Programa de Desenvolvimento Regional do Além São Francisco 1979-1982. Secretaria de Agricultura. Salvador, 1979.

BAHIA. A inserção da Bahia na evolução nacional. $2^{\mathrm{a}}$ etapa: 1890-1930. Salvador: Secretaria do Planejamento, Ciência e Tecnologia, 1980a.

BAHIA. Política de Desenvolvimento Urbano e Regional 19791983. Secretaria do Planejamento, Ciência e Tecnologia. Salvador, $1980 \mathrm{~b}$.

BAHIA. Programa de Ocupação Econômica do Oeste. Secretaria do Planejamento, Ciência e Tecnologia. Salvador, 1980 c.

BECKER, Bertha Koiffmann; EGLER, Claudio A. G. Brasil: uma nova potência regional na economia-mundo. 8. ed. Rio de Janeiro: Bertrand Brasil, 2011.

CARIBÉ, Clovis; VALE, Raquel. Oeste da Bahia: trilhando velhos e novos caminhos. Feira de Santana: UEFS Editora, 2012.

COSTA, Wanderley Messias da. O Estado e as Políticas territoriais no Brasil. 9 ed. São Paulo: Contexto, 2011.

FREITAS, A. F. Guerreiro de. Oeste da Bahia: formação histórico-cultural. Cadernos do CEAS, Salvador, v. 181, p. 59-78, maio/jun. 1999.

KRAYCHETE, Gabriel; COMERFORD, John. C. Oeste baiano. Os movimentos sociais face ao novo cenário regional. In: CORIBÉ, Clovis; VALE, Raquel. Oeste da Bahia: trilhando velhos e novos caminhos. Feira de Santana: UEFS Editora, p. 98-130, 2012.

MORAES, Antonio Carlos Robert. Geografia Pequena História Crítica. 19a. ed. São Paulo: Annablume, 2003a.

MORAES, Antonio Carlos Robert. O Sertão. Um "outro" geográfico. Terra Brasilis (Nova Série), n.4-5 ,p. 1-8, 2003b. Disponível em:<http://terrabrasilis.revues. org/341> Acesso em: 20 de janeiro de 2015.

MORAES, Antonio Carlos Robert. Território e história no Brasil. $2^{\circ}$ edição. - São Paulo: Annablume, 2005.

MORAES, Antonio Carlos Robert. Bases da formação territorial do Brasil: o território colonial brasileiro no "longo" século XVI. 2a. ed. São Paulo: Annablume, 2011a. MORAES, Antonio Carlos Robert. Geografia Histórica do Brasil: capitalismo, território e periferia. São Paulo: Annablume, 2011 b.

MORAES, Antonio Carlos Robert. Território na geografia de Milton Santos. São Paulo: Annablume, 2013.

OLIVEIRA, Waldir Freitas. História de um banco: o banco Econômico. Salvador: Museu Eugênio Teixeira Leal/ Memorial do Banco, 1993.

RÜCKERT, Aldomar Arnaldo. Políticas Territoriais, ciência e tecnologia e a ação de atores locais e regionais. O Pólo de Modernização tecnológica da Serra- Rio Grande do Sul- Brasil. Revista Sociologias, Porto Alegre, n. 11, jan/ jun 2004, p. 148-183.

RÜCKERT, Aldomar Arnaldo. Uso do Território e Políticas Territoriais Contemporâneas: alguns cenários no Brasil, União Europeia e Mercosul. Revista de Geopolítica. Ponta Grossa (PR), v.1, n.1, p. 17-32, jan/jun, 2010.

SÁNCHEZ, Joan-Eugeni. Geografía Política. Madrid: Síntesis,1992.

SANTOS, Clovis Caribé de Matos. Oeste da Bahia: modernização com (des)articulação econômica e social de uma região. 241fl. 2007. (Tese de doutorado. Programa de Pós-Graduação em Ciências Sociais, da Faculdade de Filosofia e Ciências Humanas. Universidade Federal da Bahia, 2007).

SANTOS, Clovis Caribé de Matos. Ocupação econômica, formação social e modernização agrícola. In: NEVES, E. F. Sertões da Bahia. Formação social, desenvolvimento econômico, evolução política e diversidade cultural. Salvador: Editora Arcádia, 2011, p. 283-313.

SANTOS FILHO, Milton. O processo de urbanização no Oeste Baiano. Recife: Superintendência do Desenvolvimento do Nordeste (SUDENE), 1989.

SILVA, Sylvio Bandeira de Mello; LEÃO, Sônia de Oliveira Leão; SILVA, Barbara - Christine Nentwing. Urbanização e metropolização no Estado da Bahia: evolução e dinâmica. Salvador: Centro Editorial e didático UFBA, 1989.

\section{Maria Aparecida Brito Oliveira}

Mestra em Geografia pela Universidade Federal da Bahia. Possui especialização em Dinâmica Territorial e Socioambiental do Espaço Baiano pela Universidade Estadual de Feira de Santana e licenciatura em Geografia pela Universidade do Estado da Bahia. Integra o Núcleo de Pesquisas Estado, Território e DesenvolvimentoLESTE e o Grupo DIT-Dinâmicas dos Territórios, do Instituto de Geociências da Universidade Federal da Bahia. Possui experiência de atuação no ensino de geografia e áreas afins, com ênfase na abordagem política, econômica, regional e de formação de professores. Atualmente é professora do Instituto Federal de Educação, Ciência e Tecnologia Baiano lecionando nos cursos do ensino médio/técnico e superior.

E-mail: cida_geografia@hotmail.com 